\title{
Atypical Clinical and Serological Manifestation of Pemphigus Vegetans: A Case Report and Review of the Literature
}

\author{
Rebecca Mergler $^{\mathrm{a}} \quad$ Andreas Kerstan $^{\mathrm{a}}$ Enno Schmidt ${ }^{\mathrm{b}}$ \\ Matthias Goebeler ${ }^{a}$ Sandrine Benoit ${ }^{a}$ \\ ${ }^{a}$ Department of Dermatology, Venereology and Allergology, University Hospital \\ Würzburg, Würzburg, Germany; ${ }^{b}$ Department of Dermatology, Venereology and \\ Allergology, University of Lübeck, Lübeck, Germany
}

\section{Keywords}

Desmocollin · Desmoglein $\cdot$ Pemphigus $\cdot$ Pemphigus vegetans $\cdot$ Review

\begin{abstract}
Pemphigus vegetans (PVeg) is a rare variant of pemphigus vulgaris characterized by pustules and/or papillomatous vegetations, preferentially affecting intertriginous and periorificial areas. Exceptional manifestations may be misdiagnosed resulting in delayed diagnosis and treatment. Diagnosis is confirmed by immunofluorescence and detection of anti-desmoglein (Dsg) 3 and/or anti-Dsg1 antibodies. We herein report an unusual manifestation of PVeg. At the time of first presentation, lesions were restricted to the right ring finger's tip. Although mucous membranes were initially not affected, high levels of anti-Dsg3 antibodies were detected while anti-Dsg1 and anti-desmocollin (Dsc) 1, 2, and 3 antibodies were absent. To compare our immunological findings with previous reports, all accessible Anglophone literature published since December 1988 was evaluated. We identified 52 patients suffering from
\end{abstract}


PVeg, 7 of these showed anti-Dsg3 antibodies without any mucous membrane involvement. Notably, the detection of anti-Dsg1 and anti-Dsg3 antibodies does not necessarily correlate with the involvement of skin and/or mucous membranes. This might be due to more specific and complex antibody constellations in nonclassical or atypical pemphigus.

(C) 2017 The Author(s)

Published by S. Karger AG, Basel

\section{Introduction}

Pemphigus vegetans (PVeg) is a rare variant of pemphigus vulgaris (PV) and accounts for $<5 \%$ of pemphigus cases [1]. PVeg is divided in 2 different subtypes. However, distinction of these 2 clinical forms as well as differentiation from PV is not always possible. The more frequent Neumann type displays periorificial papillomatous vegetations, whereas the Hallopeau type is characterized by pustules evolving into vegetations particularly affecting the intertriginous areas $[1,2]$. Involvement of mucous membranes occurs and resembles PV [1]. Whether PVeg is a distinct entity or just a special phenotype of PV is still controversial.

Unusual or atypical manifestations of PVeg may pose a diagnostic challenge resulting in delayed diagnosis. A broad spectrum of differential diagnoses must be considered depending on the clinical manifestation and distribution of the lesions.

As in PV, the diagnosis of PVeg is confirmed via direct and indirect immunofluorescence (IF) microscopy and detection of anti-desmoglein (Dsg) 3 and/or anti-Dsg1 antibodies [2]. In addition, anti-desmocollin (Dsc) 1, 2, and 3 antibodies were detected in some patients [3-6]. Treatment regimens of PVeg adhere to those of conventional PV [7].

We here report a case of PVeg with initially exclusive involvement of the ring finger's tip of the right hand representing per se a diagnostic challenge that was associated with an unusual constellation of anti-Dsg3 antibodies. To compare our patient's antibody profile with autoimmunological findings of previously described patients suffering from PVeg, we performed a literature research considering all cases of PVeg published in the English-speaking literature.

\section{Case Report}

A 64-year-old Caucasian man was referred with a 6-week history of a sharply bordered erythematous plaque affecting the ring finger's tip of the right hand. Despite antimicrobial treatment with several antibiotics (cefuroxime, ampicillin, clindamycin, ciprofloxacin) and anti-inflammatory topical treatment with betamethasone valerate, skin lesions progressed and finally led to loss of the nail. The patient had a medical history of perichondritis, an untreated arterial hypertension, as well as a panic disorder. Neither the patient's nor the family history was remarkable for any skin disease. Physical examination revealed a plaque with overlying crusts and annular pustules on erythematous ground on the fourth right digit (Fig. 1a). In addition, perianal papillomatous plaques were found. Mucous membranes were not involved. Typical psoriatic nail changes were absent. The patient was in otherwise good general condition. 
Bacterial swabs of the finger revealed colonization with Enterococcus faecalis, Escherichia coli, Morganella morganii, and gram-positive cocci, while tests for fungal infections were negative. Routine laboratory tests were inconspicuous. In addition to bacterial and fungal infections, differential diagnoses including vegetating herpes simplex infection, acrodermatitis continua suppurativa, pyoderma gangraenosum, Bowen's disease, and squamous cell carcinoma were considered and excluded. Histopathology showed eosinophilic pustule formation in the epidermis in concert with acantholysis and a superficial eosinophil-rich lymphocytic infiltrate (Fig. 1b) reminiscent of PVeg.

Finally, the diagnosis was confirmed by direct IF microscopy of perilesional skin revealing intercellular deposits of IgG antibodies in the epidermis (Fig. 1c). Indirect IF microscopy on monkey esophagus allowed detection of IgG antibodies binding with an intercellular pattern. Although mucous membranes were initially not involved, high levels of circulating antiDsg3 antibodies (2,644 U/ml; normal: $>20 \mathrm{U} / \mathrm{mL})$ but no anti-Dsg1 antibodies were detected by ELISA (MESACUP Desmoglein 1 and $3^{\circledR}$, MBL, Nagoya, Japan). In addition, indirect IF using Desmocollin (Dsc)-transfected HEK293 cells as substrate revealed absence of circulating IgA and IgG autoantibodies against Dsc1, -2, and -3 (data not shown). Altogether, PVeg of the Hallopeau type was diagnosed.

A high-dose intravenous steroid pulse therapy (100 mg dexamethasone on 3 consecutive days) was initiated and repeated after 2 weeks. Having ensured normal thiopurine methyltransferase activity, azathioprine was started $(1.4 \mathrm{mg} / \mathrm{kg}$ body weight per day) but had to be discontinued due to drug-related liver toxicity. Instead, mycophenolate mofetil (MMF) was administrated (2 g per day). Two weeks after the second intravenous steroid pulse, anti-Dsg3 antibody levels notably decreased to $237 \mathrm{U} / \mathrm{mL}$ (Fig. 2), and the patient was almost free of skin lesions. As maintenance therapy, steroid pulses were repeated 7 times in 4-6-week intervals. However, 6 months after initiation of treatment, disease activity increased. For the first time, the patient developed erosions of the oral mucosa going along with involvement of several fingers and aggravation of the vegetations in the perianal region. Worsening of disease was reflected by an increase of serum autoantibody levels (anti-Dsg3 IgG: 3,328 U/mL; anti-Dsg1 IgG: $30 \mathrm{U} / \mathrm{mL}$ ) (Fig. 2). The clinical course was complicated by erysipelas of the right hand. In addition, the patient experienced several depressive episodes linked to his preexisting panic disorder. Finally, therapy with rituximab, an anti-CD20antibody depleting CD20+ B lymphocytes, was initiated. Rituximab was administrated twice at a dose of $1 \mathrm{~g}$ in a 2-week interval while MMF was continued. Unfortunately, clinical response could not be assessed as the patient was lost to follow-up.

\section{Review of the Literature and Discussion}

Unusual or atypical manifestations of PVeg are prone to be misdiagnosed or misinterpreted, which may result in delayed correct diagnosis. In case of solitary lesions or uncommon localization of PVeg, the number of potential differential diagnoses is extensive. Paraneoplastic pemphigus can only be distinguished by IF microscopy. In the presented case, bacterial, fungal, and viral infections were excluded. Acrodermatitis continua suppurativa was considered, but neither the patient's nor the family history or the clinical examination was remarkable for psoriasis. Malignancy was excluded by histopathology, and pyoderma 
gangraenosum remained a diagnosis of exclusion. Finally, the diagnosis of PVeg of the Hallopeau type was established by the results of histopathology, direct IF microscopy, and serology. Strikingly, the initial detection of anti-Dsg3 antibodies in the absence of anti-Dsg1 antibodies without mucosal involvement was puzzling.

To compare our patient's antibody profile with autoimmunological findings of previously described patients suffering from PVeg, we reviewed the Anglophone literature from December 1988 to January 2017, considering all available full-text publications providing information on mucous membranes and/or skin involvement and autoantibody levels (at least anti-Dsg1 and/or anti-Dsg3 reactivity; Table 1) [2-5, 8-34].

Thirty-one publications reporting results of 52 patients were identified (PVeg, $n=48$; pemphigoid vegetans (BPVeg)/PVeg, $n=1$; paraneoplastic pemphigus/PVeg, $n=3$ ). In 35 patients, the provided information concerning clinical picture and immunological findings enabled us to correlate involvement of the skin and/or mucous membranes with anti-Dsg1 and/or anti-Dsg3 antibody levels. In 24 patients, affection of skin and mucous membranes was observed. In 1 patient, lesions were restricted to mucous membranes [10]. Ten patients suffered from skin lesions only [3, 5, 8, 13, 15, 17, 22, 31, 32]. Notably, in 7 of these, as in our patient, anti-Dsg3 antibodies were detected although mucous membranes were spared [8, $13,15,17,22,31,32]$.

These findings are not consistent with the desmoglein compensation hypothesis that explains the tissue specificity of the autoantibody-induced loss of cell adhesion in pemphigus. According to this hypothesis, Dsg3 compensates the loss of function of Dsg1 and vice versa [35]. Thus, our patient is expected to present with solely mucosal lesions.

However, in recent years our understanding of the pemphigus pathogenesis considerably increased and the "monopathogenetic" explanation has been questioned. While the compensation theory basically described acantholysis-introducing effects of anti-Dsg antibodies, actually other pathogenic effects (like induction of acanthosis or accumulation of neutrophils) of anti-Dsg antibodies must be considered. There is evidence that, apart from Dsg1 and Dsg3, additional organ-specific and non-organ-specific antigens are targeted by autoantibodies [36]. Besides Dsg 1-4, there are 3 other cadherins in the epidermal desmosomes, namely Dsc1, Dsc2, and Dsc3. Anti-Dsc3 IgG antibodies have been detected in sera of patients with atypical variants of pemphigus such as PVeg $[3,5,6]$. Moreover, anti-Dsc1 IgA antibodies were found in patients suffering from subcorneal pustular dermatosis type of IgA pemphigus [37]. In the patient presented here, no anti-Dsc1, -2 or -3 antibodies were detected in the serum via IF using Dsc-transfected HEK293 cells as substrate. However, it was recently shown that the sensitivity of novel ELISAs using recombinant, mammalian proteins was higher than that of IF [6].

As in our patient, unusual manifestations of PVeg may mimic various skin diseases and pose a diagnostic challenge. Histopathology in combination with direct and indirect IF microscopy is necessary to confirm diagnosis. Notably, the detection of anti-Dsg1 and anti-Dsg3 antibodies does not necessarily correlate with the involvement of skin and/or mucous membranes.

This might be due to more specific and complex antibody constellations in nonclassical or atypical pemphigus. The further development and implementation of new diagnostic approaches such as the detection of serum anti-Dsc antibodies on a routine basis may clarify this observation. 


\section{Acknowledgement}

This publication was funded by the German Research Foundation (DFG) and the University of Wuerzburg in the funding program Open Access Publishing.

\section{Statement of Ethics}

The authors have no ethical conflicts to disclose.

\section{Disclosure Statement}

All authors declare that there are no conflicts of interest regarding the publication of this case report.

\section{References}

1 Hammers C, Schmidt E, Borradori L: Pemphigus vegetans; in Katsambas A, Lotti T, Dessiniotu C, D'Erme A (eds): European Handbook of Dermatological Treatments. Springer, Heidelberg, 2015, pp 701-705.

-2 Zaraa I, Sellami A, Bouguerra C, Sellami MK, Chelly I, Zitouna M, Makni S, Hmida AB, Mokni M, Osman AB: Pemphigus vegetans: a clinical, histological, immunopathological and prognostic study. J Eur Acad Dermatol Venereol 2011;25:1160-1167.

3 Saruta H, Ishii N, Teye K, Ono F, Ohyama B, Koga H, Ohata C, Furumura M, Tsuruta D, Hashimoto T: Two cases of pemphigus vegetans with IgG anti-desmocollin 3 antibodies. JAMA Dermatol 2013;149:1209_ 1213.

4 Hashimoto K, Hashimoto T, Higashiyama M, Nishikawa T, Garrod DR, Yoshikawa K: Detection of antidesmocollins I and II autoantibodies in two cases of Hallopeau type pemphigus vegetans by immunoblot analysis. J Dermatol Sci 1994;7:100-106.

-5 Rafei D, Muller R, Ishii N, Llamazares M, Hashimoto T, Hertl M, Eming R: IgG autoantibodies against desmocollin 3 in pemphigus sera induce loss of keratinocyte adhesion. Am J Pathol 2011;178:718-723. Ishii N, Teye K, Fukuda S, Uehara R, Hachiya T, Koga H, Tsuchisaka A, Numata S, Ohyama B, Tateishi C, Tsuruta D, Furumura M, Hattori S, Kawakami T, Ohata C, Hahimoto T: Anti-desmocollin autoantibodies in nonclassical pemphigus. Brit J Dermatology 2015;173:59-68.

-7 Hertl M, Jedlickova H, Karpati S, Marinovic B, Uzun S, Yayli S, Mimouni D, Borradori L, Feliciani C, Ioannides D, Joly P, Kowalewski C, Zambruno G, Zilikens D, Jonkman MF: Pemphigus. S2 Guideline for diagnosis and treatment - guided by the European Dermatology Forum (EDF) in cooperation with the European Academy of Dermatology and Venereology (EADV). J Eur Acad Dermatol Venereol 2015;29:404-415.

-8 Mori M, Mariotti G, Grandi V, Gunnella S, Maio V: Pemphigus vegetans of the scalp. J Eur Acad Dermatol Venereol 2016;30:320-386.

$\checkmark 9$ Mendes-Bastos P, Amaro C, Fernandes C: Cobblestone mouth: an exuberant oral presentation of pemphigus vegetans. Actas Dermosifiliogr 2015;106:72-73.

10 Apalla Z, Sotiriou E, Lazaridou E, Manousari A, Trigoni A, Papagarifallou I, Ioannides D: Pemphigus vegetans of the tongue: a diagnostic and therapeutic challenge. Int J Dermatol 2013;52:350-351.

11 Wolz MM, Camilleri MJ, McEvoy MT, Bruce AJ: Pemphigus vegetans variant of IgA pemphigus, a variant of IgA pemphigus and other autoimmune blistering disorders. Am J Dermatopathol 2013;35:e53-e56.

12 Son YM, Kang HK, Yun JH, Roh JY, Lee JR: The Neumann type of pemphigus vegetans treated with combination of dapsone and steroid. Ann Dermatol 2011;23:310-313.

13 Wei J, He CD, Wei HC, Li B, Wang YK, Jin GY, Zheng S, Chen HD: Facial pemphigus vegetans. J Dermatol 2011;38:615-618. 

vegetans - immunopathological findings in a rare variant of pemphigus vulgaris. J Dtsch Dermatol Ges 2010;8:179-183.

15 Torres T, Ferreira M, Sanches M, Selores M: Pemphigus vegetans in a patient with colonic cancer. Indian J Dermatol Venereol Leprol 2009;75:603-605.

-16 Adachi M, Tsuruta D, Imanishi H, Ishii M, Kobayashi H: Necrotizing fasciitis caused by Cryptococcus neoformans in a patient with pemphigus vegetans. Clin Exp Dermatol 2009;34:751-753. pemphigus vegetans. J Plast Reconstr Aesthet Surg 2009;62:506-508. Cozzani E, Christana K, Mastrogiacomo A, Rampini P, Drosera M, Casu M, Murialdo G, Parodi A: Pemphigus vegetans Neumann type with anti-desmoglein and anti-periplakin autoantibodies. Eur J Dermatol 2007; 17:530-533.

19 Koga C, Izu K, Kabashima K, Tokura Y: Pemphigus vegetans associated with gastric cancer. J Eur Acad Dermatol Venereol 2007;21:1288-1289.

Kaiser J, Kaatz M, Elsner P, Ziemer M: Complete remission of drug-resistant Pemphigus vegetans treated by extracorporeal photopheresis. J Eur Acad Dermatol Venereol 2007;21:843-844. Duparc A, Boivin S, Gilbert D, Piette F, Delaporte E: Paraneoplastic pemphigus with pemphigus vegetans-like lesions revealing non-Hodgkin lymphoma. Eur J Dermatol 2006;16:698-699. vegetans confined to the scalp. Int J Dermatol 2006;45:1008-1009. Morizane S, Yamamoto T, Hisamatsu Y, Tsuji K, Oono T, Hashimoto T, Iwatsuki K: Pemphigus vegetans with IgG and IgA antidesmoglein 3 antibodies. Br J Dermatol 2005;153:1236-1237. Powell AM, Albert S, Oyama N, Sakuma-Oyama Y, Bhogal B, Black MM: Paraneoplastic pemphigus secondary to fludarabine evolving into unusual oral pemphigus vegetans. J Eur Acad Dermatol Venereol 2004;18:360-364.

25 Torok L, Husz S, Ocsai H, Krischner A, Kiss M: Pemphigus vegetans presenting as acrodermatitis continua suppurativa. Eur J Dermatol 2003;13:579-581. Sapadin AN, Anhalt GJ: Paraneoplastic pemphigus with a pemphigus vegetans-like plaque as the only cutaneous manifestation. J Am Acad Dermatol 1998;39:867-871. Ohata Y, Komiya H, Kawahara Y, Watanabe K, Nishikawa T, Hashimoto T: A case of Neumann type pemphigus vegetans showing reactivity with the $130 \mathrm{kD}$ pemphigus vulgaris antigen. Acta Derm Venereol 1996;76:169-170. Mahe A, Flageul B, Prost C, Intrator L, Bobin P: Pemphigus vegetans in an HIV-1-infected man. Clin Exp Dermatol 1994;19:447.

-29 Hashizume H, Iwatsuki K, Takigawa M: Epidermal antigens and complement-binding anti-intercellular antibodies in pemphigus vegetans, Hallopeau type. Br J Dermatol 1993;129:739-743.

-30 Parodi A, Stanley JR, Ciaccio M, Rebora A: Epidermal antigens in pemphigus vegetans. Report of a case. Br J Dermatol 1988;119:799-802.

31 Hatano Y, Ishikawa K, Koga H, Ishii N, Hashimoto T, Takeo N, Shimada H, Sakai T, Okamoto O, Fujiwara S: A case of concurrent pemphigoid vegetans and pemphigus vegetans resolving without oral corticosteroid. Br J Dermatol 2014;170:1192-1194.

-32 Salah LA: Vegetating inguinal and perianal lesions: a quiz. Acta Derm Venerol 2015;95:507-509.

-33 Akkari H, Belkahla M, Youssef M, Lataief A, Soua Y, Sriha B, Belhadjali H, Zili J: Pemphigus vegetans associated with Gitelman syndrome. Indian J Dermatol Venerol Leprol 2015;81:655.

-34 von Köckritz A, Ständer S, Zeidler C, Metze D, Luger T, Bonsmann G: Successful monotherapy of pemphigus vegetans with minocycline and nicotinamide. J Eur Acad Dermatol Venerol 2017;31:85-88. Mahoney MG, Wang Z, Rothenberger K, Koch PJ, Amagai M, Stanley JR: Explanations for the clinical and microscopic localization of lesions in pemphigus foliaceus and vulgaris. J Clin Invest 1999;103:461468.

-36 Grando SA: Pemphigus autoimmunity: hypotheses and realities. Autoimmunity 2012;45:7-35.

-37 Hashimoto T, Kiyokawa C, Mori O, Miyasato M, Chidgey MA, Garrod DR, Kobayashi Y, Komori K, Ishii K, Amagai M, Nishikawa T: Human desmocollin 1 (Dsc1) is an autoantigen for the subcorneal pustular dermatosis type of IgA pemphigus. J Invest Dermatol 1997;109:127-131. 


\section{Case Reports in Dermatology}
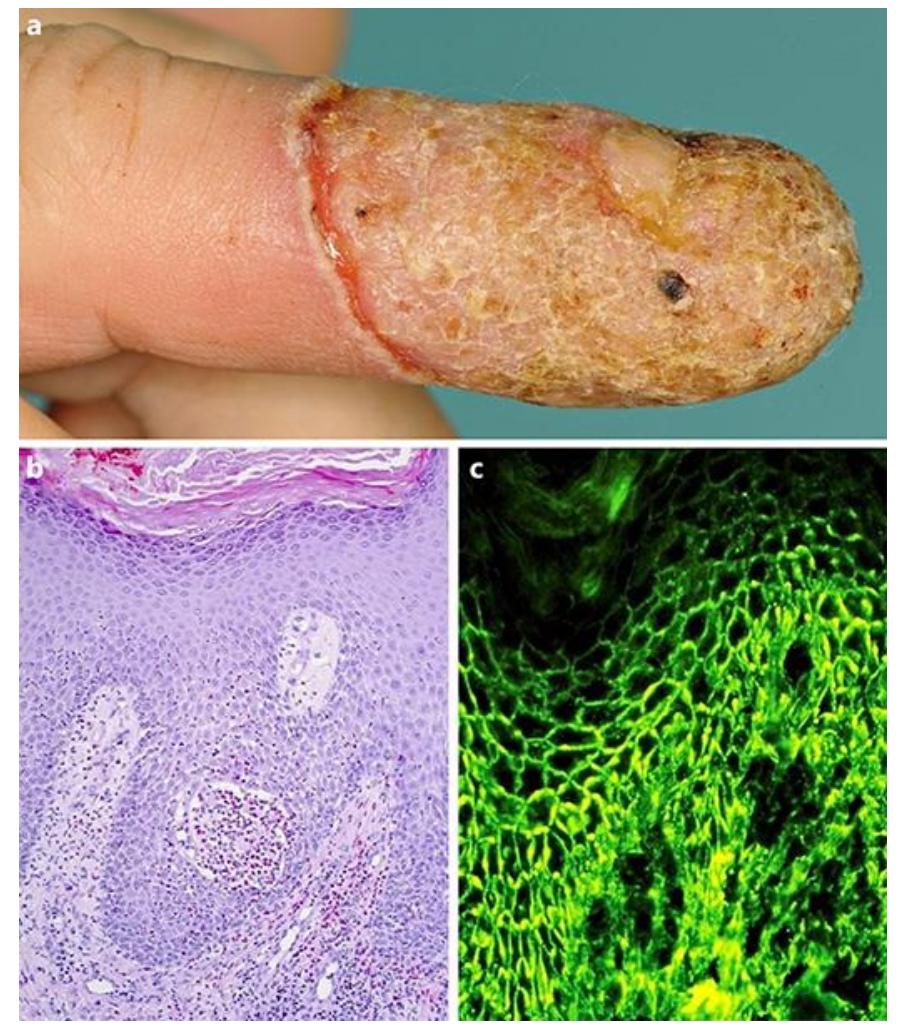

Fig. 1. a Plaque with overlying crusts and annular pustules on erythematous ground on the fourth right digit. b Histopathology revealed prominent acanthosis with an intraepidermal eosinophilic pustule accompanied by surrounding eosinophilic spongiosis and a superficial eosinophil-rich inflammatory infiltrate and acantholysis. c Direct IF microscopy of perilesional skin showing intercellular deposits of IgG antibodies in the epidermis. IF, immunofluorescence. 


\section{Case Reports in Dermatology}

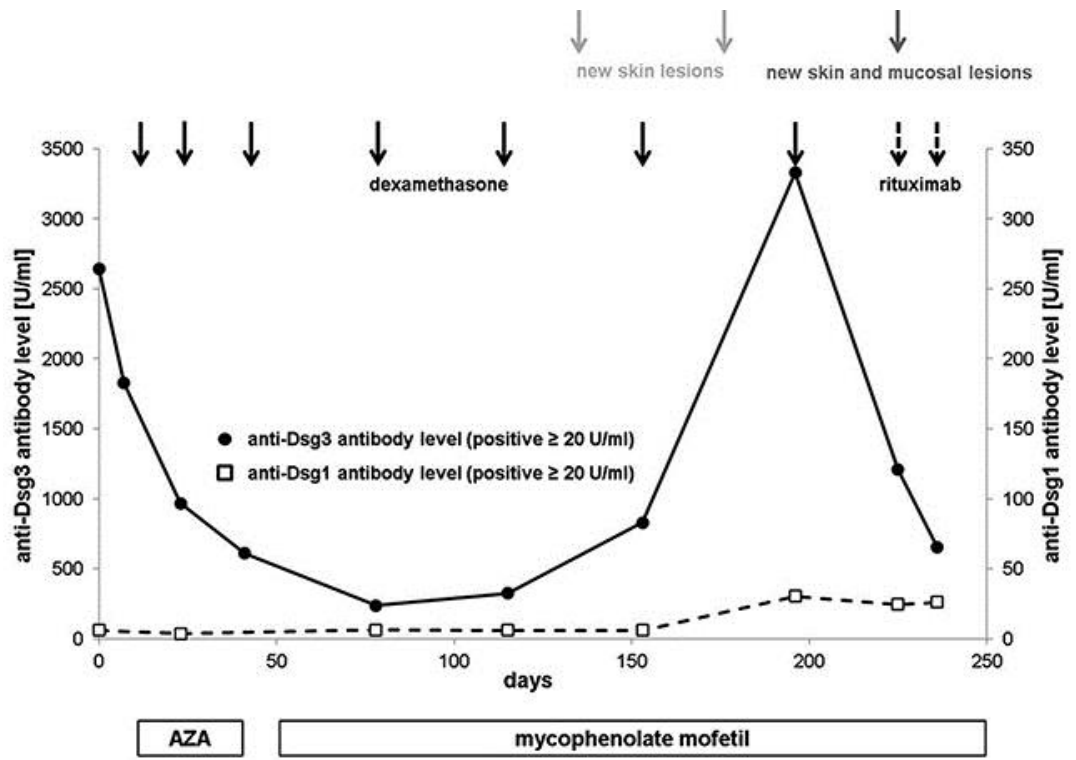

Fig. 2. Serum autoantibody levels during the course of the disease. Black dots indicate the level of anti-Dsg3 antibodies. White squares indicate the level of anti-Dsg1 antibodies. Adjuvant treatment consisted of azathioprine or mycophenolate mofetil. Each solid-lined black arrow indicates a steroid pulse (100 mg dexamethasone on 3 consecutive days). The dashed arrows refer to rituximab administration $(1 \mathrm{~g})$. Disease activity is indicated by gray arrows. AZA, adjuvant treatment consisted of azathioprine. 
Table 1. IF and antibody profiles in patients suffering from PVeg

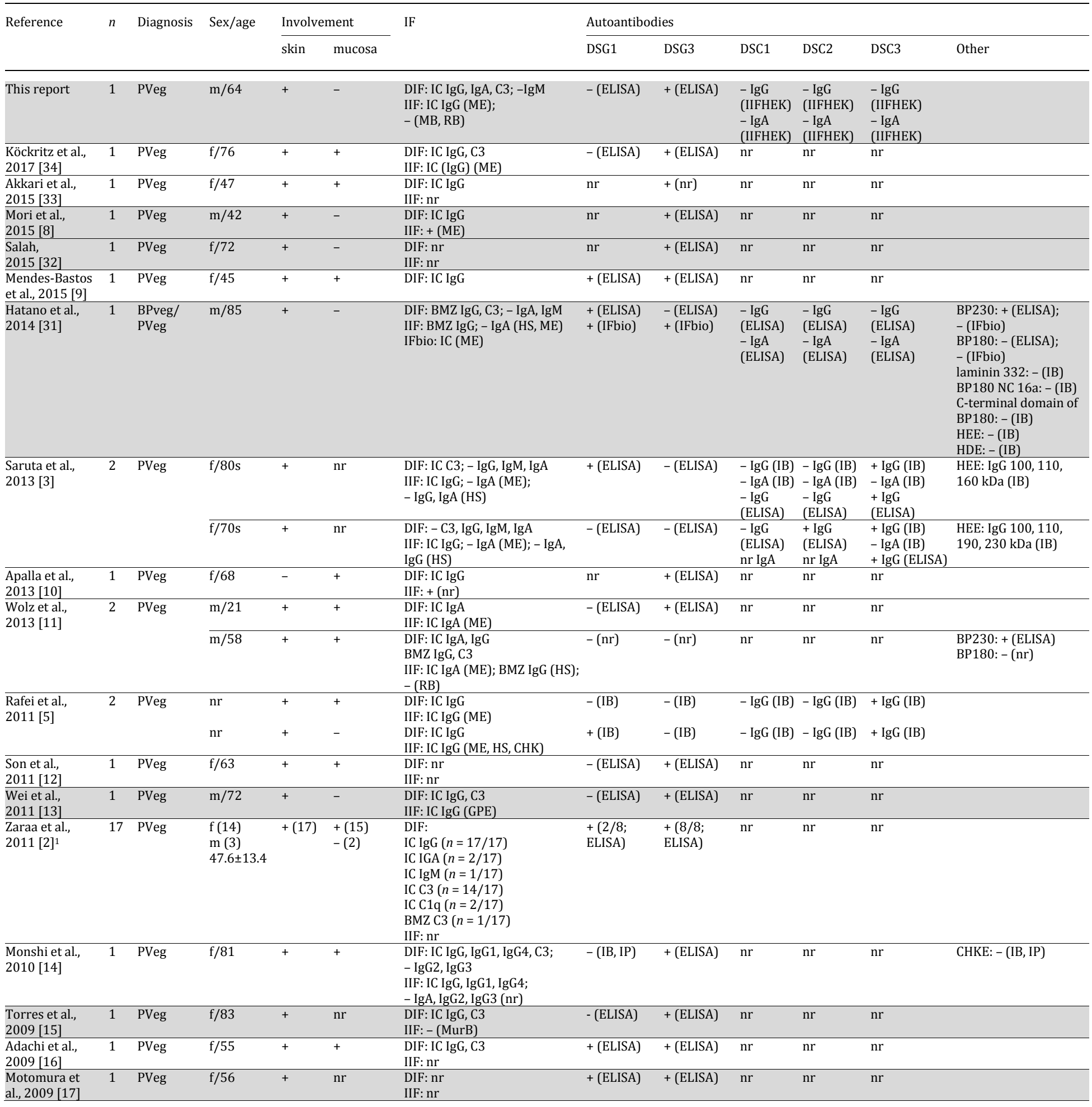




\section{Case Reports in Dermatology}

\begin{tabular}{|c|c|c|c|c|c|c|c|c|c|c|c|c|}
\hline \multirow[t]{2}{*}{$\begin{array}{l}\text { Cozzani et al., } \\
2007[18]\end{array}$} & \multirow[t]{2}{*}{2} & \multirow[t]{2}{*}{ PVeg } & \multirow{2}{*}{$\begin{array}{l}\mathrm{m} / 72 \\
\mathrm{f} / 77\end{array}$} & + & + & \multirow{2}{*}{$\begin{array}{l}\text { DIF: IC IgG } \\
\text { BMZ C3 } \\
\text { IIF: + (ME, RB) } \\
\text { DIF: IC IgG, C3 } \\
\text { BMZ C3 } \\
\text { IIF: + (ME, RB) }\end{array}$} & \multirow{2}{*}{$\begin{array}{l}+ \text { (ELISA) } \\
-(\mathrm{IB}) \\
-(\text { ELISA) } \\
- \text { (IB) }\end{array}$} & \multirow{2}{*}{$\begin{array}{l}+(\text { ELISA }) \\
+(\mathrm{IB}) \\
+(\text { ELISA }) \\
+(\mathrm{IB})\end{array}$} & $\mathrm{nr}$ & $\mathrm{nr}$ & $\mathrm{nr}$ & $\begin{array}{l}\text { HEE: } 130,190 \\
\mathrm{kDa}(\mathrm{IB})\end{array}$ \\
\hline & & & & + & + & & & & $\mathrm{nr}$ & $\mathrm{nr}$ & $\mathrm{nr}$ & $\begin{array}{l}\text { HEE: } 130,190 \\
\text { kDa (IB) }\end{array}$ \\
\hline $\begin{array}{l}\text { Koga et al., } \\
2007 \text { [19] }\end{array}$ & 1 & PVeg & $\mathrm{m} / 72$ & + & + & $\begin{array}{l}\text { DIF: IC IgG, C3c, C3d; } \\
\text { - IgA, IgM } \\
\text { IIF: IC IgG (nr) }\end{array}$ & $-($ ELISA) & $+($ ELISA) & $\mathrm{nr}$ & $\mathrm{nr}$ & $\mathrm{nr}$ & \\
\hline $\begin{array}{l}\text { Kaiser et al., } \\
2007[20]\end{array}$ & 1 & PVeg & $\mathrm{f} / 49$ & + & + & $\begin{array}{l}\text { DIF: IC IgG } \\
\text { IIF: IgG (nr) }\end{array}$ & $\mathrm{nr}$ & $+($ ELISA) & $\mathrm{nr}$ & $\mathrm{nr}$ & $\mathrm{nr}$ & \\
\hline $\begin{array}{l}\text { Duparc et al., } \\
2006[21]\end{array}$ & 1 & $\begin{array}{l}\text { PNP/ } \\
\text { PVeg }\end{array}$ & $f / 54$ & + & + & $\begin{array}{l}\text { DIF: IC IgG } \\
\text { IIF: IC IgG (RB); } \\
\text { - (HS) }\end{array}$ & $\begin{array}{l}-(\text { ELISA) } \\
-(\mathrm{IB})\end{array}$ & $\begin{array}{l}+(\text { ELISA }) \\
+(\text { IB) }\end{array}$ & $\mathrm{nr}$ & $\mathrm{nr}$ & $\mathrm{nr}$ & $\begin{array}{l}\text { HEE: 130, 190, 210, } \\
230 \mathrm{kDa} \text { (IB) }\end{array}$ \\
\hline $\begin{array}{l}\text { Danopoulou et } \\
\text { al., 2006 [22] }\end{array}$ & 1 & PVeg & $\mathrm{f} / 54$ & + & - & $\begin{array}{l}\text { DIF: IC IgG, C3 } \\
\text { IIF: } \mathrm{nr}\end{array}$ & $-($ ELISA) & $+($ ELISA) & $\mathrm{nr}$ & $\mathrm{nr}$ & $\mathrm{nr}$ & \\
\hline $\begin{array}{l}\text { Morizane et al., } \\
2005 \text { [23] }\end{array}$ & 1 & PVeg & $\mathrm{m} / 67$ & + & + & $\begin{array}{l}\text { DIF: IC IgG, IgA, C3 } \\
\text { IIF: - IgG, IgA, IgM, C3 (nr) }\end{array}$ & $\begin{array}{l}- \text { IgG, IgA } \\
\text { (ELISA) } \\
- \text { IgG, IgA } \\
\text { (IB) }\end{array}$ & $\begin{array}{l}+ \text { IgG, IgA } \\
\text { (ELISA) } \\
- \text { IgG, IgA } \\
\text { (IB) }\end{array}$ & $\begin{array}{l}- \text { IgG } \\
\text { (ELISA) } \\
- \text { IgA } \\
\text { (ELISA) }\end{array}$ & $\begin{array}{l}- \text { IgG } \\
\text { (ELISA) } \\
- \text { IgA } \\
\text { (ELISA) }\end{array}$ & $\begin{array}{l}\text { - IgG } \\
\text { (ELISA) } \\
- \text { IgA } \\
\text { (ELISA) }\end{array}$ & HEE: - (IB) \\
\hline $\begin{array}{l}\text { Powell et al., } \\
2004 \text { [24] }\end{array}$ & 1 & $\begin{array}{l}\text { PNP/ } \\
\text { PVeg }\end{array}$ & $\mathrm{m} / 69$ & + & + & $\begin{array}{l}\text { DIF: IC IgG, C3 } \\
\text { BMZ IgG, C3 } \\
\text { IIF: IC IgG (ME, RB, HS) } \\
\text { BMZ IgG (HS) }\end{array}$ & $\begin{array}{l}+(\text { ELISA) } \\
-(\mathrm{IB})\end{array}$ & $\begin{array}{l}+(\text { ELISA) } \\
+(\mathrm{IB})\end{array}$ & $\mathrm{nr}$ & $\mathrm{nr}$ & $\mathrm{nr}$ & $\begin{array}{l}\text { HEE: } 130,170,190, \\
210,250,190 \mathrm{kDa}(\mathrm{IB})\end{array}$ \\
\hline $\begin{array}{l}\text { Török et al., } \\
2003 \text { [25] }\end{array}$ & 1 & PVeg & $\mathrm{f} / 51$ & + & + & $\begin{array}{l}\text { DIF: IC IgG, C3 } \\
\text { IIF: IC IgG (ME, HS) }\end{array}$ & $-(\mathrm{IB})$ & $+(\mathrm{IB})$ & $\mathrm{nr}$ & $\mathrm{nr}$ & $\mathrm{nr}$ & HEE: 130 kDa (IB) \\
\hline $\begin{array}{l}\text { Sapadin et al., } \\
1998[26]\end{array}$ & 1 & $\begin{array}{l}\text { PNP/ } \\
\text { PVeg }\end{array}$ & $\mathrm{m} / 54$ & + & + & $\begin{array}{l}\text { DIF: IC IgG } \\
\text { IIF: + (ME, RB) }\end{array}$ & $-(\mathrm{IB})$ & $-(\mathrm{IB})$ & $\mathrm{nr}$ & $\mathrm{nr}$ & $\mathrm{nr}$ & $\begin{array}{l}\text { nr: }+190,210,230 \\
250 \mathrm{kDa}(\mathrm{IP})\end{array}$ \\
\hline $\begin{array}{l}\text { Ohata et al., } \\
1996 \text { [27] }\end{array}$ & 1 & PVeg & $\mathrm{m} / 30$ & + & + & $\begin{array}{l}\text { DIF: IC IgG, C3 } \\
\text { IIF: IC IgG (HS) }\end{array}$ & $-(\mathrm{IB})$ & $+(\mathrm{IB})$ & $\mathrm{nr}$ & nr. & $\mathrm{nr}$ & HEE: 130 kDa (IB) \\
\hline $\begin{array}{l}\text { Mahé et al., } \\
1994 \text { [28] }\end{array}$ & 1 & PVeg & $\mathrm{m} / 31$ & + & + & $\begin{array}{l}\text { DIF: IC IgG } \\
\text { BMZ C3 } \\
\text { IIF: IC + (HS, RB) }\end{array}$ & $-(\mathrm{IB})$ & $+(\mathrm{IB})$ & $\mathrm{nr}$ & $\mathrm{nr}$ & $\mathrm{nr}$ & BTE: $130,190 \mathrm{kDa}$ (IB) \\
\hline $\begin{array}{l}\text { Hashimoto et } \\
\text { al., } 1994 \text { [4] }\end{array}$ & 2 & PVeg & $f / 67$ & + & + & $\begin{array}{l}\text { DIF: IC IgG } \\
\text { IIF: IC IgG (HS) }\end{array}$ & $-(\mathrm{IB})$ & $+(\mathrm{IB})$ & $\begin{array}{l}+\operatorname{IgG}(\mathrm{IB}) \\
\mathrm{nr} \operatorname{IgA}\end{array}$ & $\begin{array}{l}+\operatorname{IgG}(\mathrm{IB}) \\
\mathrm{nr} \operatorname{IgA}\end{array}$ & $\mathrm{nr}$ & $\begin{array}{l}\text { HEE: } 130 \mathrm{kDa}(\mathrm{IB}) \\
\text { BDP: } 105,115,135 \text {, } \\
150 \mathrm{kDa}(\mathrm{IB})\end{array}$ \\
\hline & & & $\mathrm{f} / 33$ & + & + & $\begin{array}{l}\text { DIF: IC IgG } \\
\text { IIF: IC IgG (HS) }\end{array}$ & $-(\mathrm{IB})$ & $+(\mathrm{IB})$ & $\begin{array}{l}+\operatorname{IgG}(\mathrm{IB}) \\
\text { nr IgA }\end{array}$ & $\begin{array}{l}+\operatorname{IgG}(\mathrm{IB}) \\
\mathrm{nr} \operatorname{IgA}\end{array}$ & $\mathrm{nr}$ & $\begin{array}{l}\text { HEE: } 130 \mathrm{kDa} \text { (IB) } \\
\text { BDP: } 105,115,150 \\
\text { kDa (IB) }\end{array}$ \\
\hline $\begin{array}{l}\text { Hashizume et } \\
\text { al., } 1993 \text { [29] }\end{array}$ & 1 & PVeg & $\mathrm{f} / 34$ & + & + & $\begin{array}{l}\text { DIF: IC IgG, C3 } \\
\text { IIF: IC IgG (CHK, GPL) }\end{array}$ & $-(\mathrm{IB})$ & $+(\mathrm{IB})$ & $\mathrm{nr}$ & $\mathrm{nr}$ & $\mathrm{nr}$ & HEE: 130 kDa (IB) \\
\hline $\begin{array}{l}\text { Parodi et al., } \\
1988[30]\end{array}$ & 1 & PVeg & f/55 & + & + & $\begin{array}{l}\text { DIF: IC IgG, C3 } \\
\text { IIF: IC IgG (ME) }\end{array}$ & $\mathrm{nr}$ & $+(\mathrm{IP})$ & $\mathrm{nr}$ & $\mathrm{nr}$ & $\mathrm{nr}$ & $\begin{array}{l}\text { CHKE: } 85,130 \mathrm{kDa} \\
\text { and other not specified } \\
\text { chains (IP) }\end{array}$ \\
\hline
\end{tabular}

Gray shading marks cases where anti-Dsg3 antibodies were detected although mucous membranes were spared. The employed methods of detection are given in parentheses.

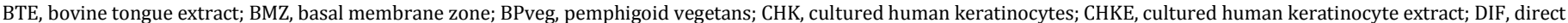

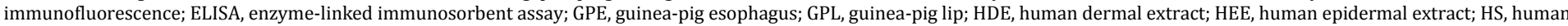

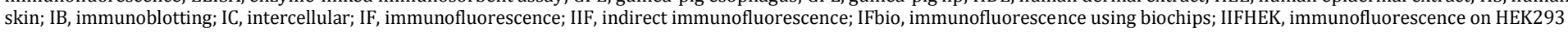

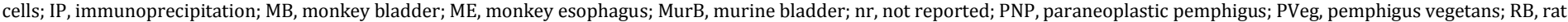
bladder.

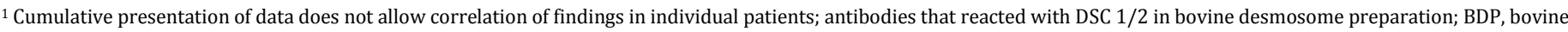
desmosome preparation 